\title{
Localización con semilla radioactiva (LSR) de lesiones no palpables de la mama- Desarrollo e implementación del programa en la República Argentina
}

\section{Radioactive Seed Localization for Nonpalpable Breast Lesions: Program Development \& Implementation in Argentina}

\author{
María Soledad Muñoz ${ }^{10}$ Carlos Enrique Rossi ${ }^{1}{ }^{10}$ Marcelo Muñoz $^{1(0)}$ \\ ${ }^{1}$ Centro de Imágenes Médicas, Rosario, Santa Fe, Argentina \\ Rev Argent Radiol 2019;83:102-112. \\ Address for correspondence María Soledad Muñoz, PhD, Centro de \\ Imágenes Médicas, Tucuman 1840, Rosario, Santa Fe, Argentina \\ (e-mail: soledadmunoz2@gmail.com).
}

\begin{abstract}
Resumen
Palabras clave

- cáncer de mamal diagnóstico por imágenes

- cáncer de mamal patología

- cáncer de mama/ cirugía

- medicina nuclear/ procedimientos

- ultrasonografíal procedimientos
\end{abstract}

El intervencionismo en mama se inició con la localización preoperatoria de lesiones no palpables.

En una segunda etapa, el desarrollo de técnicas de biopsias en las tres modalidades (mamografía, ultrasonido y resonancia magnética), reforzaron las indicaciones de localización de lesiones con histología ya confirmada.

La técnica de localización en Argentina se basó casi exclusivamente en la inserción de alambres con arpones e inyección de carbón.

A partir del año 2001, se ofreció como alternativa a las localizaciones con arpones la inserción de semilla de lodo-125, considerando las ventajas para la paciente, el cirujano y el sistema hospitalario al desacoplar los turnos de quirófano y servicios de imágenes, otorgando acceso a cualquier cuadrante con incisiones cosméticas.

La provisión del isótopo es la clave para instalar y atender la demanda de los usuarios, una vez que han conocido los méritos del procedimiento.

En todos los ámbitos y distintos países, se verificó una lenta incorporación a la rutina de localización de lesiones con material radioactivo, primariamente por las regulaciones fundamentales y justificadas para la adquisición del isótopo.

En nuestro medio y en una labor conjunta con la Autoridad Regulatoria Nuclear (ARN), logramos finalmente, en el año 2017, el reconocimiento de la práctica.

Revisamos la bibliografía, describimos la técnica y la logística para lograr autorización de aquellos centros interesados en aplicar un procedimiento universalmente adoptado por sus ventajas respecto a los métodos tradicionales.
(D) María Soledad Muñoz's ORCID is https://orcid.org/0000-00032143-5161.

(D) Carlos Enrique Rossi's ORCID is https://orcid.org/0000-0002-28640929.

(D) Marcelo Muñoz's ORCID is https://orcid.org/0000-0003-21435161. received

November 27, 2018

accepted

May 31, 2019
DOI https://doi.org/

10.1055/s-0039-1693137.

ISSN 1852-9992.
Copyright (c) 2019, Sociedad Argentina de Radiología. Publicado por Thieme Revinter Publicações Ltda., Rio de Janeiro, Brazil. Todos los derechos reservados.
License terms

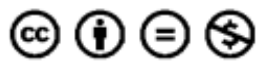


Abstract

\section{Keywords}

- breast neoplasms/ diagnostic imaging

- breast neoplasms /pathology

- breast

- neoplasms/surgery

- radionuclide imaging/methods

- ultrasonography/ methods
Diagnostic intervention in breast disease started with preoperative localization of nonpalpable lesions.

Later, with the histological diagnosis obtained through biopsy techniques in mammography, ultrasound and magnetic resonance imaging, the localization of lesions has become a must.

Traditionally, in Argentina, the localization technique was exclusively based on the insertion of harpoon-shaped guided wires and carbon suspension.

Since 2001, the iodine- 125 radioactive seed localization has emerged as a reliable and advantageous alternative for the patient, the surgeon and the hospital system, reducing scheduling conflicts between the breast imaging department and the surgical department, and allowing access to any quadrant with cosmetic incisions.

The isotope provision is the key to satisfying the users demand, once they have known the merits of the procedure.

The implementation of radioactive material for the localization of lesions has been tardy in all fields and in different countries, mainly due to justified regulations related to the acquisition of the isotope.

As a result of joint efforts with the Autoridad Regulatoria Nuclear (Nuclear Regulatory Authority), the practice finally gained its deserved recognition in 2017.

We conducted a review of the existing literature and described the technique and the logistics to obtain the approval of the sites that were interested in the deployment of a widely used procedure that has proved to be more advantageous than traditional methods.

\section{Introducción}

El desarrollo de la localización preoperatoria de lesiones de mama fue un prerrequisito para la aceptación y crecimiento de la mamografía como cribado, concepto fundamental que se debió aplicar en las demás modalidades en uso (ultrasonido y resonancia magnética). ${ }^{1}$

En la década del '70 comenzaron las primeras publicaciones en los Estados Unidos a partir del desarrollo e inventiva de cuatro reconocidos autores, en distintos diseños de arpones metálicos, constituyendo en la actualidad la técnica de localización más difundida y adoptada. ${ }^{1,2}$

En nuestro país realizamos, en 1984, la primera marcación de lesiones no palpables en la ciudad de Rosario con arpones metálicos, técnica que fue paulatinamente incorporada en nuestra región (-Fig. $\mathbf{1}$ ).

En abril de 2002, la Escuela Europea de Oncología y el Instituto de Oncología de Milán presentó en Argentina, a cargo del Dr. G. Paganelli, la localización de lesiones de mama con Tecnecio-99 (Tc-99), el mismo radioisótopo utilizado en la detección de ganglio centinela, pero marcando macroagreagado de albúmina (MAA). La técnica fue publicada en junio de ese mismo año. ${ }^{3}$

En 2004 comenzamos, en la ciudad de Rosario y a pedido de cirujanos expertos, a realizar la localización conjunta del ganglio centinela y lesión de la mama con Tc99 (-Fig. 2).

Las dos técnicas de localización del tumor no palpable, tanto la marcación con alambre como la marcación con Tecnecio MAA, presentan limitaciones.
Con los arpones, la paciente debe soportar el alambre extruido que le impide higienizarse, el cirujano debe inevitablemente confiar en el trayecto del arpón según decisión, habilidad y experiencia del radiólogo y el sistema hospitalario debe conciliar los turnos del quirófano y del servicio de diagnóstico por imágenes debido a que el arpón tiene un tiempo acotado desde su inserción hasta su remoción.

Por otra parte, la solución de Tc y albúmina difunde en el sector de la inyección (-Fig. 3), condicionando resecciones más extensas, a la vez que compite (por ser el mismo isótopo), con la señal del ganglio centinela. Al ser objetivable solo con el detector de radioactividad, le debemos incorporar un reparo radiográfico (radiopaco), para documentar la correcta localización y guiar al patólogo en su labor (-Fig. 3).

Con anterioridad, en 2001, los departamentos de Cirugía y Radiología de la Universidad de South Florida, Tampa, Estados Unidos, comunicaron la utilización de semillas con Iodo125 para la marcación preoperatoria, que resuelve las limitaciones mencionadas de las técnicas precedentes y, desde entonces hasta la fecha, se reproducen las publicaciones, meta-análisis e indicaciones. ${ }^{3-16}$

La industria acompañó con el desarrollo de sondas de detección para ganglio centinela con Tc-99 que discriminan además las señales emitidas por el isótopo de Iodo-125. ${ }^{17}$

Entre sus ventajas reconocidas, debemos mencionar que la semilla de Iodo-125 (-Fig.4) es detectable puntualmente con cualquier método de imágenes, localiza la lesión o el área a remover, con cualquier modalidad (mamografía, ecografía y resonancia magnética), no es necesario que la inserción sea efectuada el mismo día de la cirugía (puede ser realizada 


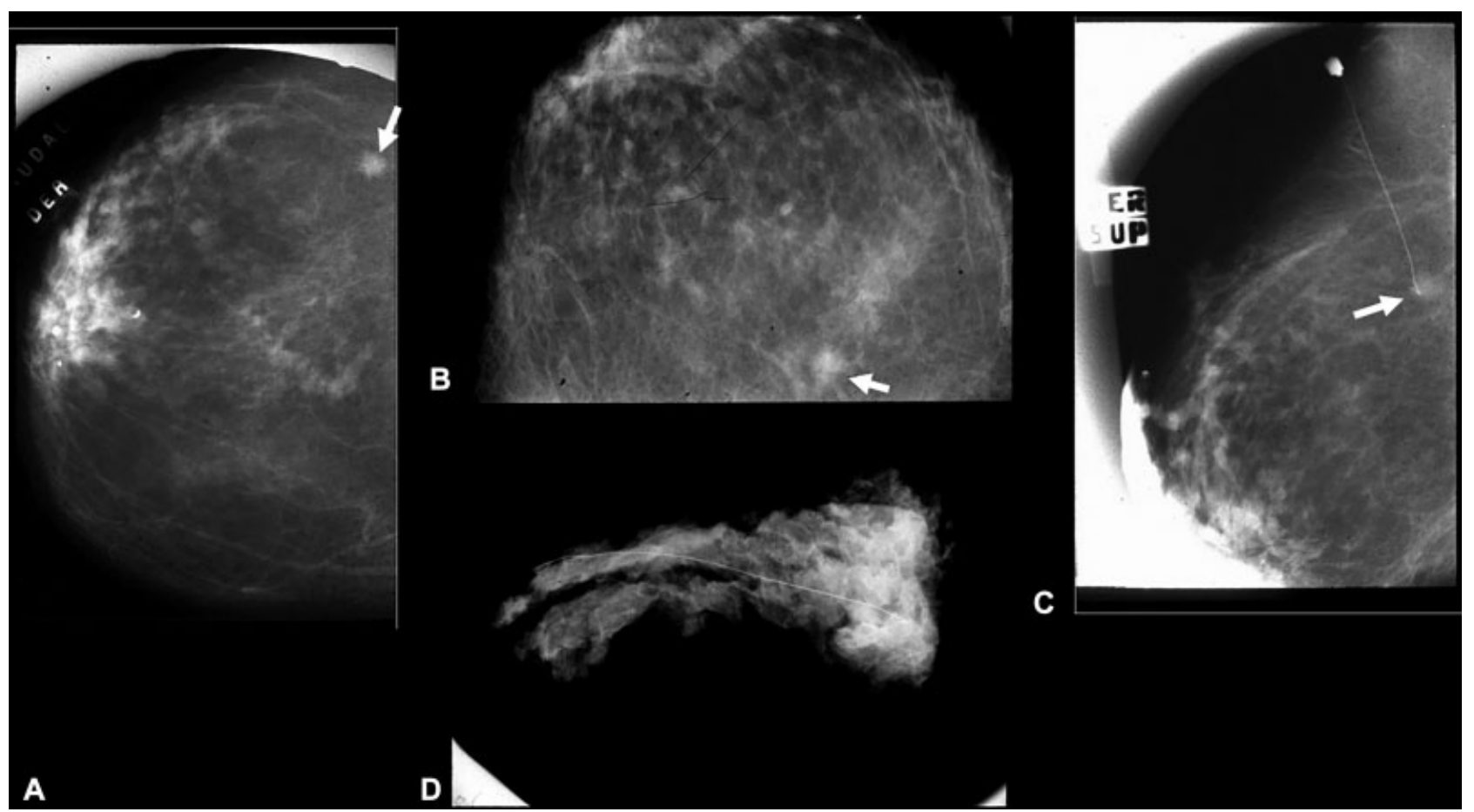

Fig. 1 Primera localización con alambre en ciudad de Rosario, en el año 1984. (A) Lateral. (B) Cráneo-caudal con nódulo espiculado en cuadrante supero externo de la mama derecha (flechas blancas). (C) Ingreso en cráneo-caudal, alambre con su extremo en el nódulo (flecha blanca). (D) Radiografía con todo el alambre incluido en el segmento resecado.

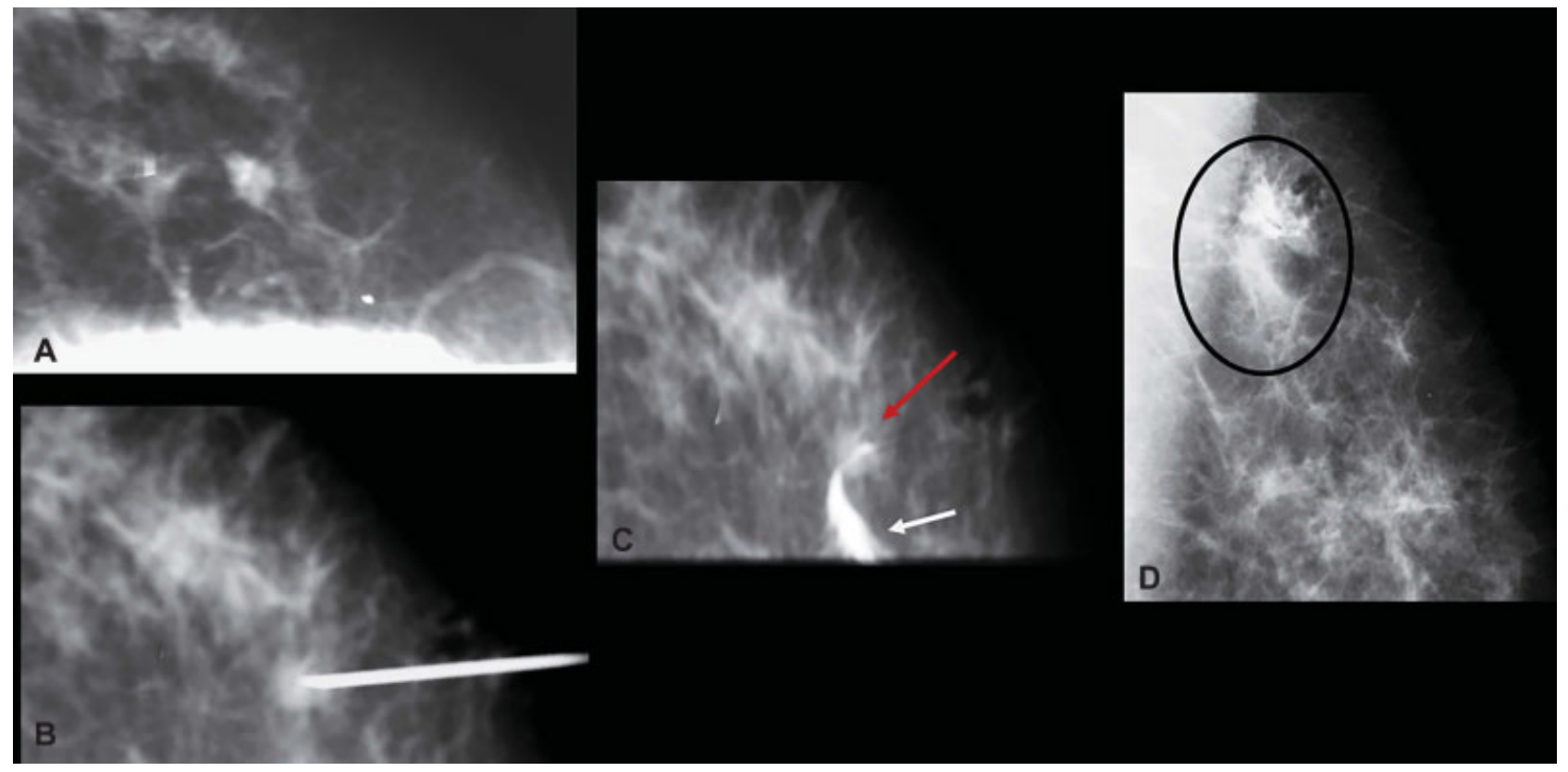

Fig. 2 ROLL localizando de un nódulo en mama izquierda, Rosario, año 2003. (A, B) Nódulo con la aguja. (C) Inyección de solución de Tc99y medio de contraste iodado ( $C$ y D), cráneo-caudal y lateral con la solución difundiendo por el sector.

hasta cinco días antes), desacoplando los tiempos entre la colocación de la semilla y su remoción quirúrgica. Además, permite al cirujano planear la incisión independientemente del punto de entrada de la aguja, con acceso a cualquier cuadrante con incisiones cosméticas. ${ }^{2}$

Estamos utilizando una fuente que decae por captura electrónica, emitiendo rayos gamma con un pico de $27 \mathrm{keV}$ y vida media de 60 días.
La baja dosis asociada al uso de semillas 125 en la localización de lesiones no palpables ha hecho del procedimiento un método seguro, tanto para la paciente como para los operadores. Se debe discernir en cuanto a la exposición/dosis del paciente y la del personal involucrado.

La dosis que reciba la paciente en el tejido mamario sano circundante a la lesión depende de la actividad de la semilla y del tiempo que la semilla haya estado implantada. Una 


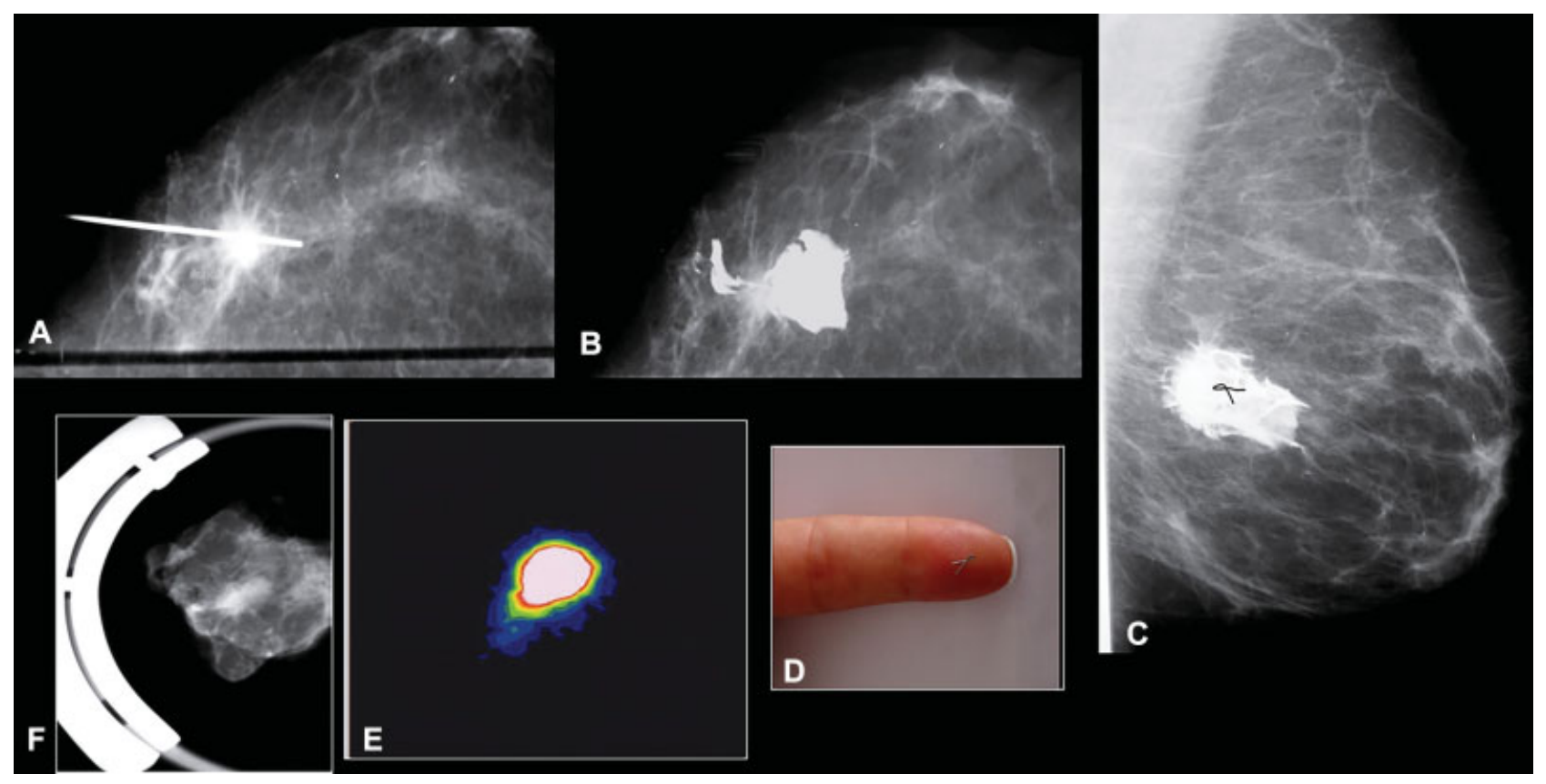

Fig. 3 ROLL localizando un nódulo en hora 3 de mama izquierda, Rosario año 2004. (A) Inyección de solución de Tc99y medio de contraste iodado. (B) Craneocaudal. (C) Lateral con la solución difundiendo alrededor de la lesión (oculta por el contraste), proyección del micro-arpón. (D) Micro arpón, (E y F) centellograma y radiografía del segmento resecado.

\section{Semilla : Cápsula de titanio soldada en sus extremos, de $0.8 \mathrm{~mm}$ de diámetro por 4,5 mm de longitud alojando lodo 125}

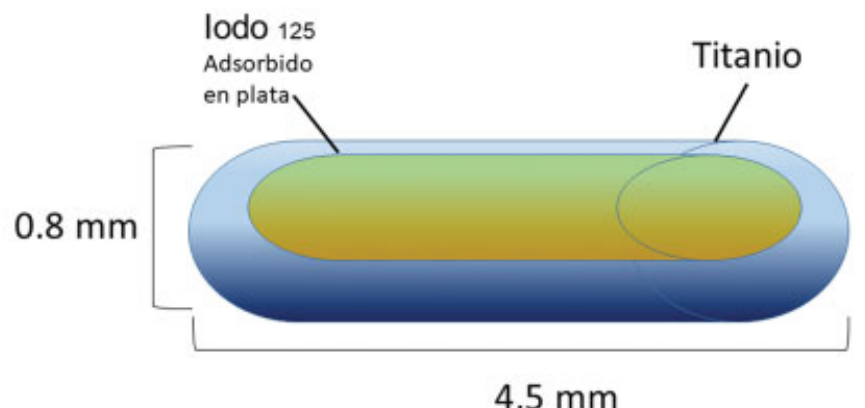

Fig. 4 Semilla con lodo 125 (adaptado de Braquibac- Laboratory. Bacon).

semilla típica de 3,7 MBq, implantada en una lesión pequeña $(2 \mathrm{~cm})$, por 24 horas, dará una dosis máxima de aproximadamente de 3 cGy. Esa dosis máxima puntual es comparable a la dosis máxima en piel por una mamografía en las dos incidencias (alrededor de 2 cGy). ${ }^{10,18,19}$

La dosis mínima durante la manipulación por parte de personal entrenado y la dosis en piel máxima del paciente una vez implantada es del orden de micro-grays, por lo que no se requieren precauciones especiales luego de la implantación.

La dosis en superficie del paciente es inferior a $10 \mu \mathrm{Sv}$ (límite de exención del control regulatorio de la Autoridad Regulatoria Nuclear (ARN)), que resulta 500 veces menor a la dosis permitida para todo el cuerpo por año ( $5 \mathrm{mSv} / \mathrm{año})$.

Esos valores se deben comparar con las dosis recibidas en una radiografía de tórax (200 $\mu \mathrm{Sv})$.

\section{Requisitos y aspectos técnicos}

Se verificó una lenta incorporación a la rutina de localización de lesiones con material radioactivo, debido, tal vez, a la combinación de dificultades para la adquisición del isótopo y la pericia técnica adecuada. ${ }^{2}$

La provisión del isótopo es la clave para instalar y atender la demanda de los usuarios, una vez que han conocido los méritos del procedimiento.

En nuestro país, la semilla de Iodo-125 está calificada como fuente sellada de uso terapéutico, más comúnmente en braquiterapia de cáncer de próstata, a cargo de urólogos y especialistas en terapia radiante entrenados y reconocidos por la ARN.

Los médicos especialistas en medicina nuclear diagnóstica pueden utilizar solo fuentes no selladas (Tc-99, por ejemplo), por lo cual debimos conseguir para la fuente 
sellada de Iodo-125 su extensión de uso terapéutico a uso diagnóstico, por cuanto la provisión de la semilla y mantener su stock fue la clave para instalar y atender la demanda de los usuarios.

Así, se llevó a cabo un proceso legislativo que comenzó en el año 2013 ante la ARN, acordando finalmente, en el mes de marzo de 2017, un protocolo preliminar consensuado y que consistió en realizar, bajo la tutoría de un médico autorizado y con experiencia en braquiterapia, a asistir a 2 (dos) implantes terapéuticos prostáticos y a realizar 5 (cinco) localizaciones de lesiones mamarias, adjuntando la certificación con los datos de cada uno de los procedimientos.

Los aspectos técnicos se lograron acordando una labor conjunta entre radiólogos entrenados en técnicas de localización y biopsias guiadas con imágenes, conjuntamente con cirujanos dedicados y artesanos en cirugías conservadoras, y expertos en el manejo de sonda de detección de ganglio centinela. También fue fundamental la colaboración de patólogos dispuestos para la recuperación de la semilla alojada en la pieza operatoria.

Por ser una técnica innovadora, comenzamos contactando a cirujanos confiables y confiados en nuestra experiencia en intervencionismo mamario, con reuniones personalizadas, explicando el desarrollo del procedimiento en todas sus etapas, los riesgos de radiación y contaminación de los operadores y su entorno.

Seleccionamos conjuntamente a las pacientes, a quienes se les explicó la técnica, beneficios y riesgos y solicitó su consentimiento informado por escrito.
Las cánulas $18 \mathrm{G}$ con mandril deben ser provistas con un limitador para alojar la semilla (que se retira al alcanzar el blanco previsto) y se obtura su extremo con cera de hueso estéril (-Fig. 5).

Los blancos deben ser rigurosamente alcanzados, con una tolerancia de $\pm 10 \mathrm{~mm}$, a diferencia del arpón, que debe ser alojado pasando la lesión. (-Fig. 6)

Se detecta con la sonda el sitio de máxima actividad y se tatúa la piel. La paciente puede higienizarse y se le recomienda que repita el tatuaje si le es factible (-Fig. 7). No existen indicaciones adicionales por la actividad del isótopo.

Se documenta con el par radiográfico en cráneo-caudal y perfil $\left(90^{\circ}\right)$, al $100 \%$, tamaño real, sin magnificación y se marcan en las placas las distancias respectivas al pezón y línea media.

Es fundamental, en los primeros procedimientos, acompañar personalmente al cirujano, para analizar la documentación, ingresando al quirófano, controlar los parámetros de la sonda (que se deben conmutar si tiene además ganglio centinela marcado con Tc-99).

Al momento de resección de la lesión, se le pide al cirujano que controle la actividad metabólica de la pieza quirúrgica, que debe ser máxima, y en el lecho quirúrgico, donde debería ser nula (-Fig. 8). Se procede luego a pesar la pieza quirúrgica en una balanza digital (-Fig. 9).

Se debe radiografiar la pieza (mientras el cirujano se dedica al ganglio centinela), previamente a la sección del patólogo a quien, si está presente, se asiste con la radiografía y/o con la sonda para localizar y remover la semilla (-Fig. 10).
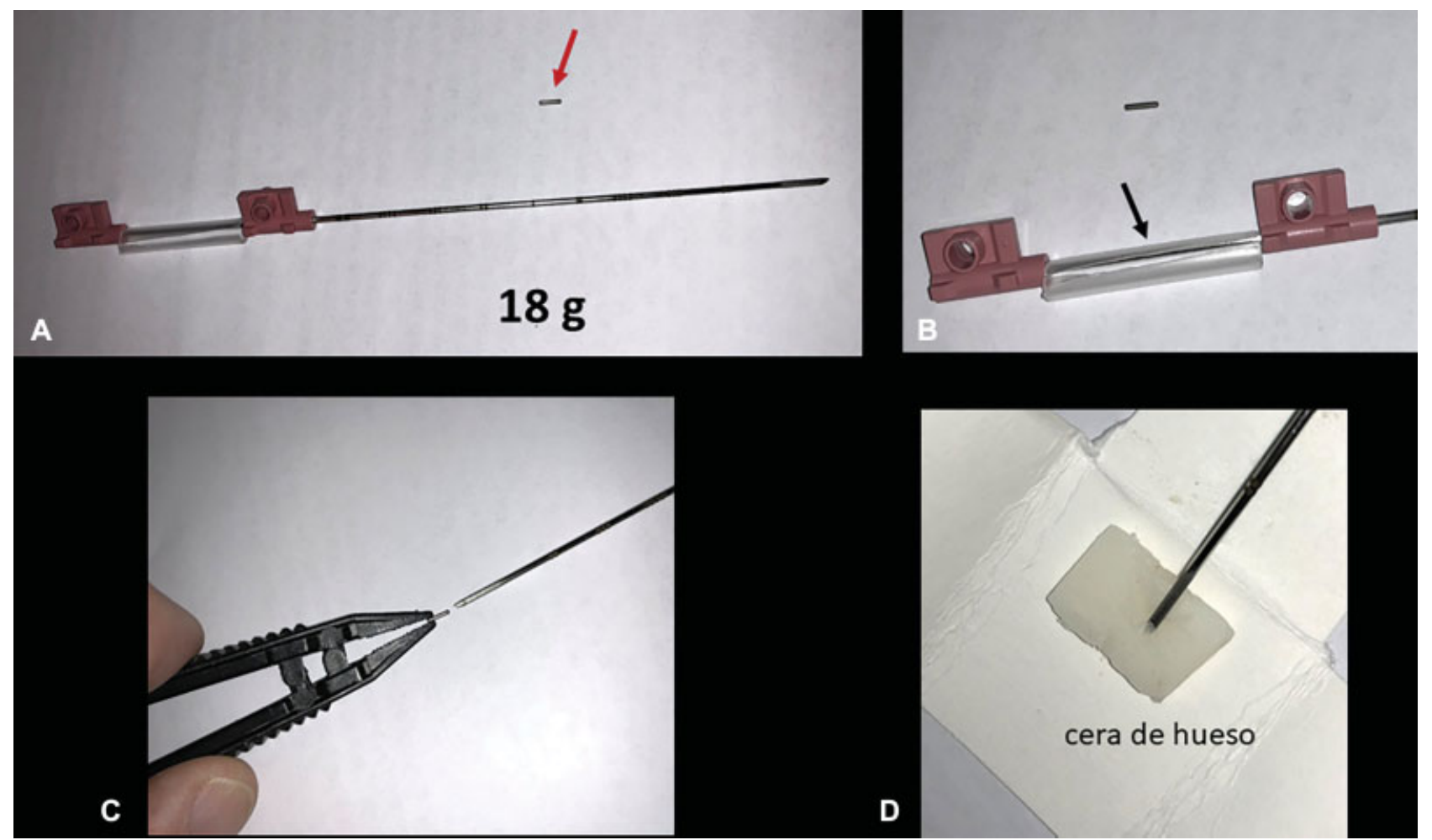

Fig. 5 (A) Semilla y aguja 18 gauge. (B) Tubo plástico limitando el trayecto del mandril (flecha). (C) Inserción de la semilla. (D) Tapón del extremo de la aguja con cera de hueso estéril. 

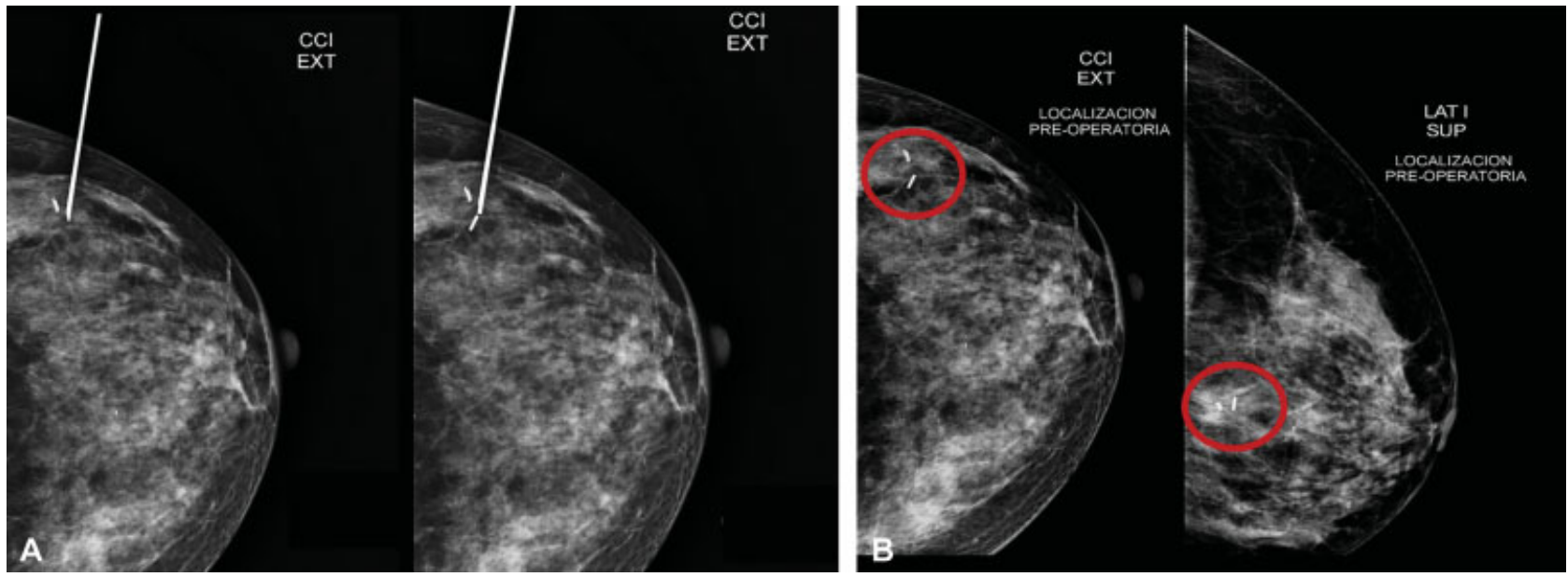

Fig.6 (A) Localización de microcalcificaciones remanentes en vecindad de clip post-biopsia. (B) Mamografías cráneocaudal y lateral adjuntadas para el quirófano.

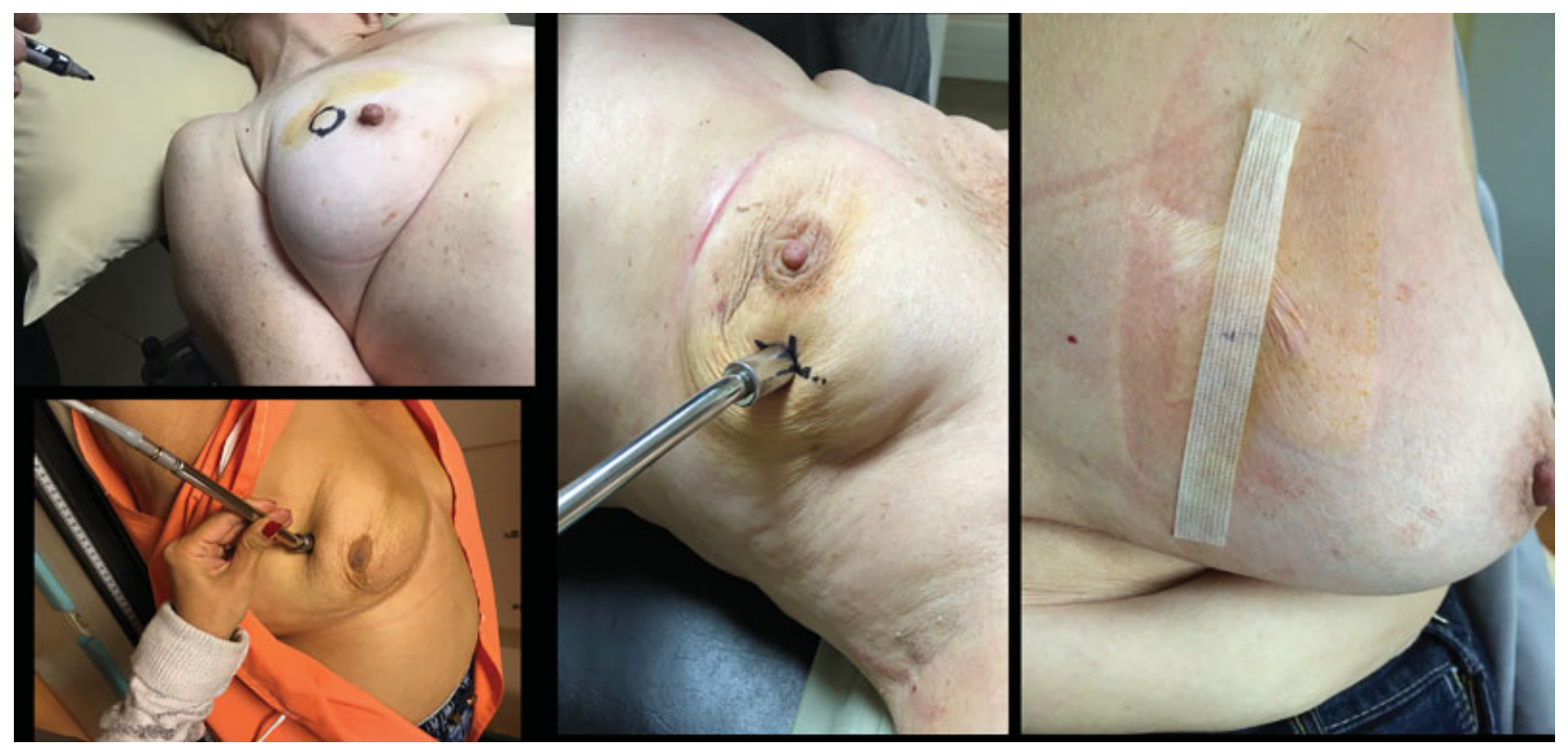

Fig. 7 Detección con sonda de la máxima actividad y tatuaje en la piel (la paciente no debe soportar alambre extruido).

Si el patólogo no está presente, se coloca la pieza en recipiente plomado y etiquetado, junto a la radiografía de la pieza, para que recupere la semilla, cuando él disponga y en su laboratorio.

Todo el personal involucrado, como instrumentistas, circulantes, técnicos radiólogos y de laboratorio deben ser instruidos en la inocuidad y riesgo nulo que implica la actividad de la semilla de Iodo-125y del ganglio centinela marcado con Tc-99.

La primera etapa finaliza cuando la semilla retorna a su depósito inicial.

Entrenamos a técnicos radiólogos en todas las etapas, para que acompañen a los cirujanos en lo sucesivo una vez que han alcanzado la meseta de entrenamiento, que generalmente es muy rápida ( 3 a 4 procedimientos).

Finalmente, el 2 de junio de 2017, concluimos la quinta localización de este ciclo, solicitada por la ARN para autorizar la práctica en nuestro país.
En septiembre de 2017, la ARN reconoció oficialmente y autorizó al especialista en medicina nuclear y director de nuestro centro a realizar la práctica y poder adquirir las semillas de Iodo-125 para uso diagnóstico.

La extensión del Permiso Individual para fuentes selladas con fines diagnósticos es otorgada por la ARN a un médico reconocido con permiso previo y lo habilita a adquirir la semilla de Iodo-125 con fines diagnósticos. Además, debe extender la Licencia de Operación para fuentes selladas, con ese fin.

El médico especialista con Permiso Individual puede designar y controlar a los médicos intervencionistas e instruir y difundir las medidas de seguridad en el manejo del isótopo. ${ }^{18,19}$

La logística exige requisitos y su registro, debe constar en el "Manual de gestión y calidad" de la instalación, a disposición del control de la ARN: consentimiento informado y firmado por el paciente, tipo de lesión (nódulo, microcalcificaciones, lesiones biopsiadas previamente), modalidad con la que realiza (mamografía, ecografía, resonancia magnética), actividad de 


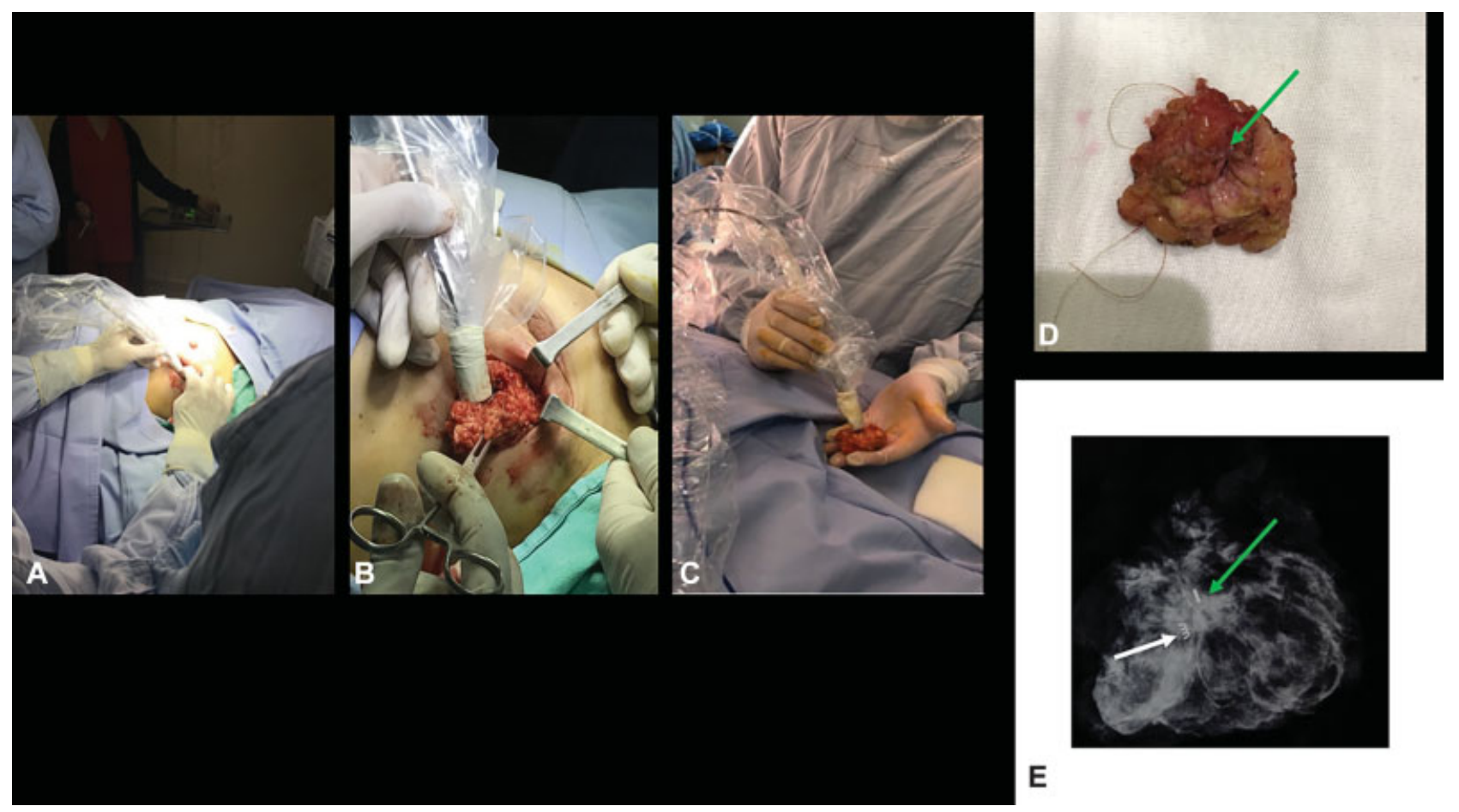

Fig. 8 (A y B) Localización de la semilla con la sonda gamma. (C) Control de la actividad de la semilla en el segmento. (D) Volumen de la resección. (E) Radiografía del segmento con el clip post biopsia (flecha blanca) y semilla (flecha verde).

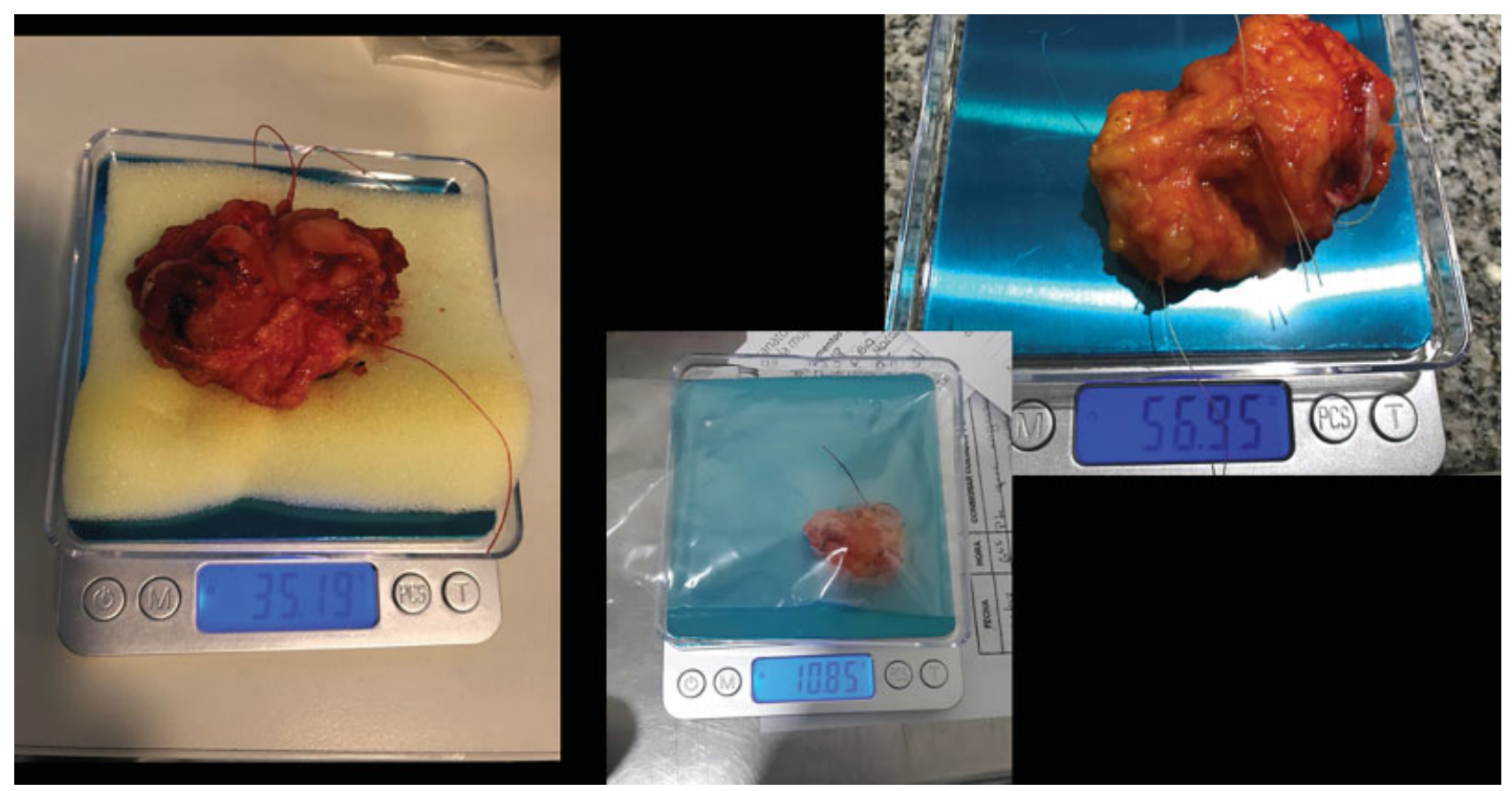

Fig. 9 Pesaje de la muestra en balanza digital.

la semilla, fechas de su inserción y remoción, médico que realiza la práctica y cirujano, duración de acto quirúrgico y volumen resecado, documentación radiográfica de la pieza operatoria alojando la lesión y la semilla, e informe del patólogo.

En nuestra experiencia, desde agosto de 2017 hasta septiembre de 2018 hemos realizado 50 procedimientos, 22 localizados mediante ecografía, 28 localizados bajo mamografía, a requerimiento de 12 cirujanos mastólogos que han ponderado la práctica (-Figs.11 and 12). En tres pacientes se insertaron dos semillas en la misma mama, como "semillas paréntesis" para delimitar un área o para señalar dos lesiones separadas (-Fig. 13). ${ }^{20}$

En esta serie no hemos registrado complicaciones de la técnica, como sección y/o pérdida de la semilla, dificultad de localizar el blanco con mamografía y ecografía (enfatizamos la colocación de clips post biopsia con US para reconocer el blanco) y desplazamientos o migración de la semilla. 


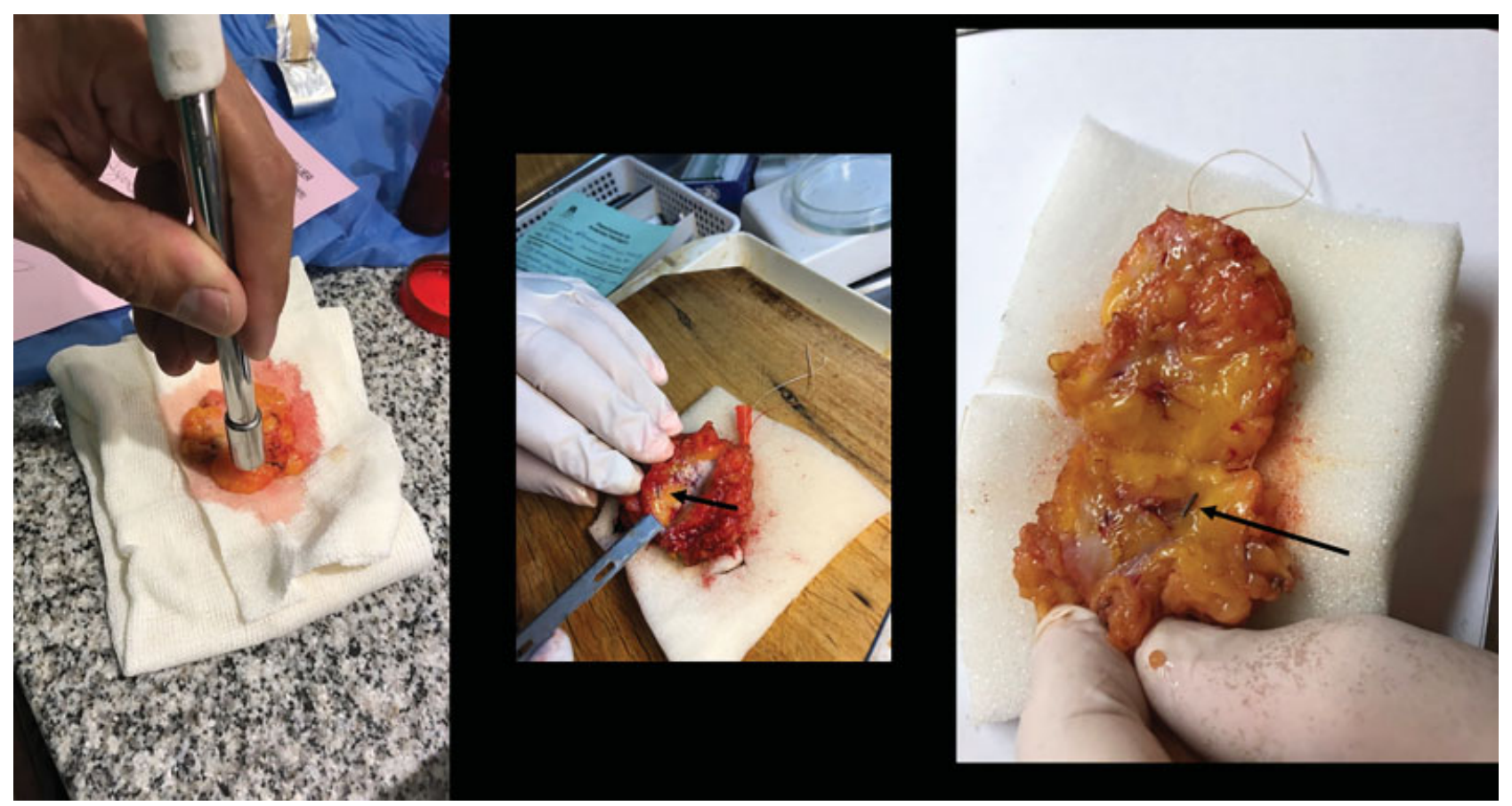

Fig. 10 Labor del patólogo. (A) Utilización de la sonda de gamma probe para localizar la semilla en el segmento. (B y C) Sección para exponer la semilla (flecha).
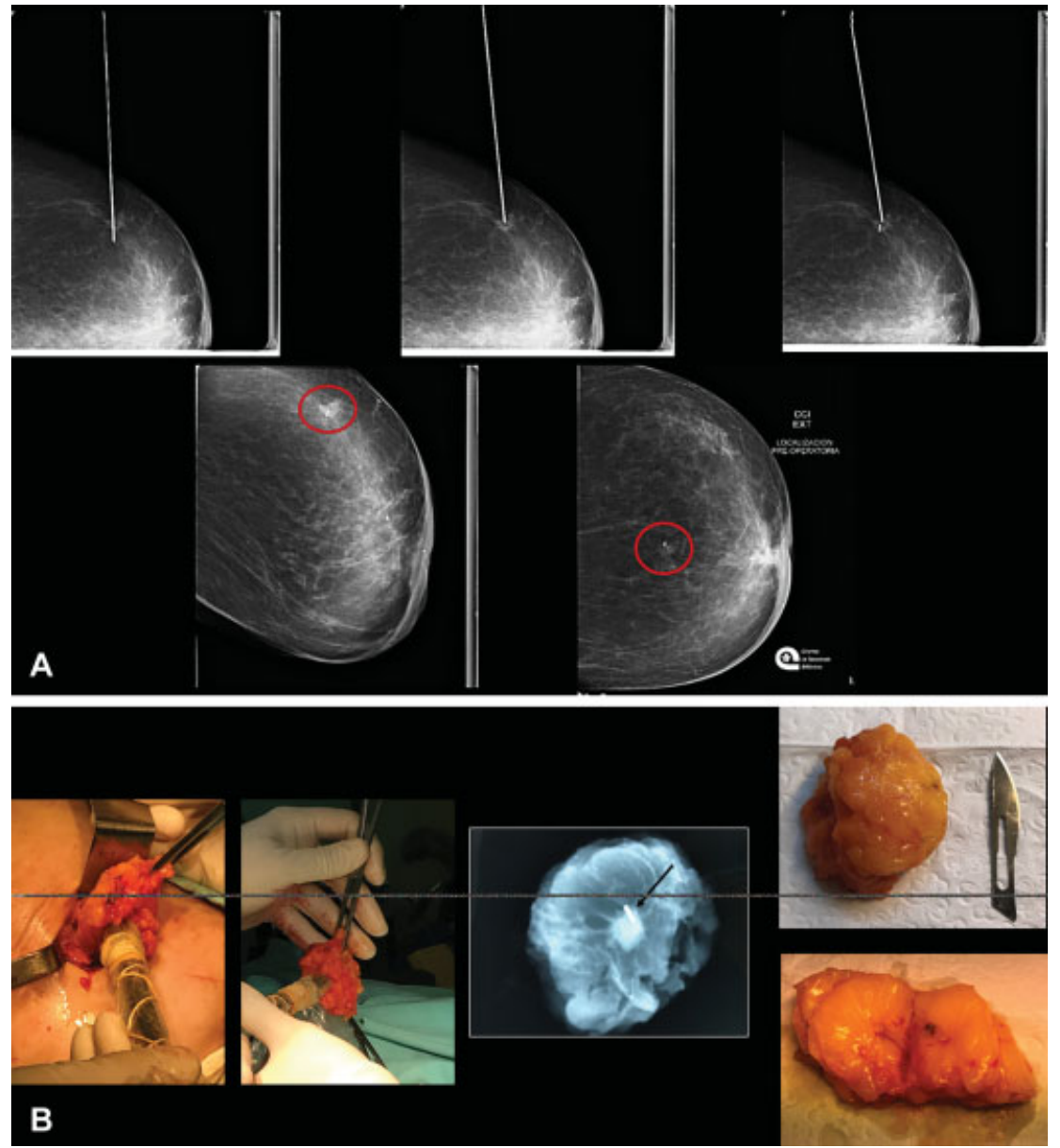

Fig. 11 (A) Localización de nódulo en hora 12 de mama izquierda. (B) Localización de la semilla en quirófano y pieza operatoria.

En 30 casos se marcaron conjuntamente la lesión con la semilla de Iodo-125y el ganglio centinela con Tc-99. Las sondas empleadas y comercialmente disponibles en nuestro país, seleccionando la ventana apropiada, 

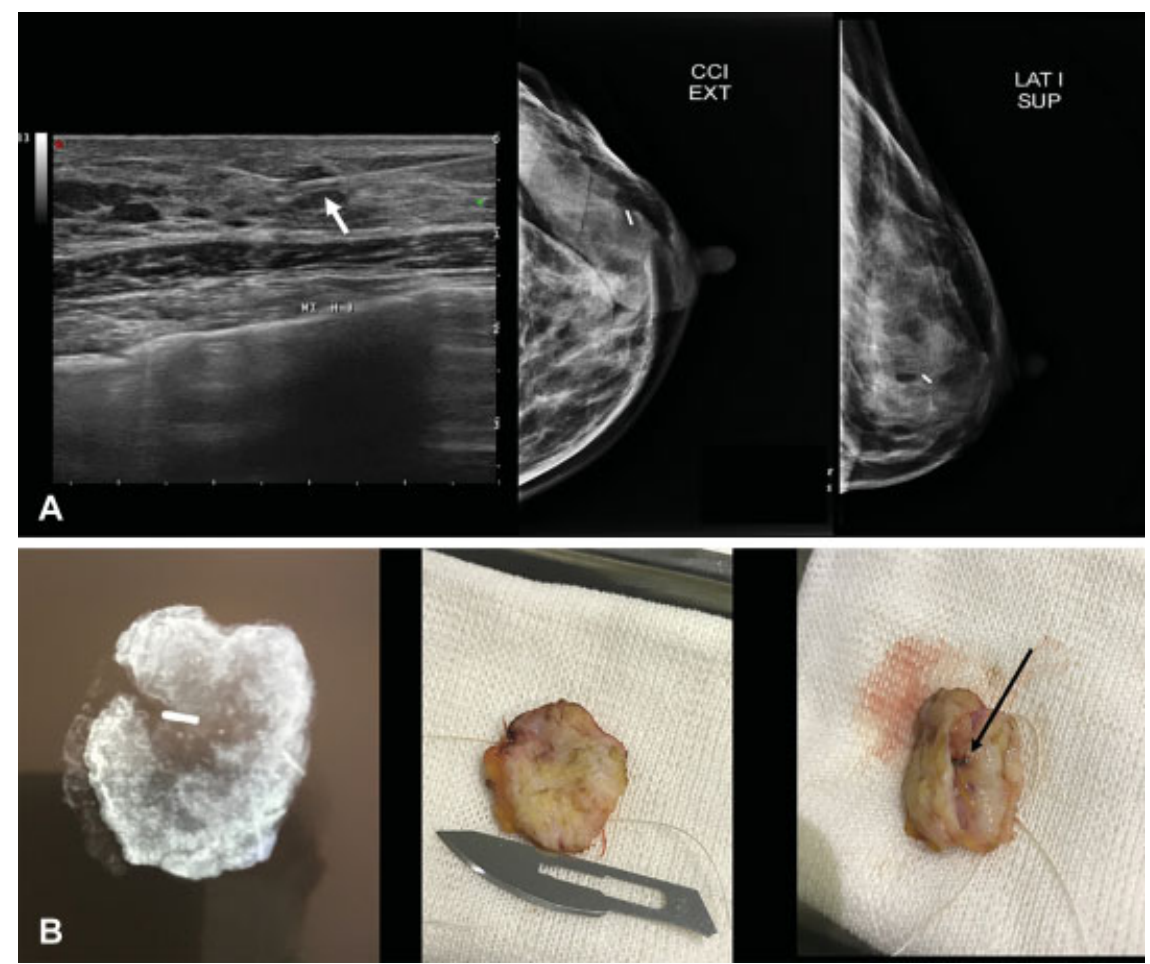

Fig. 12 (A) Localización de nódulo con ecografía y mamografías de control. (B) Pieza operatoria.
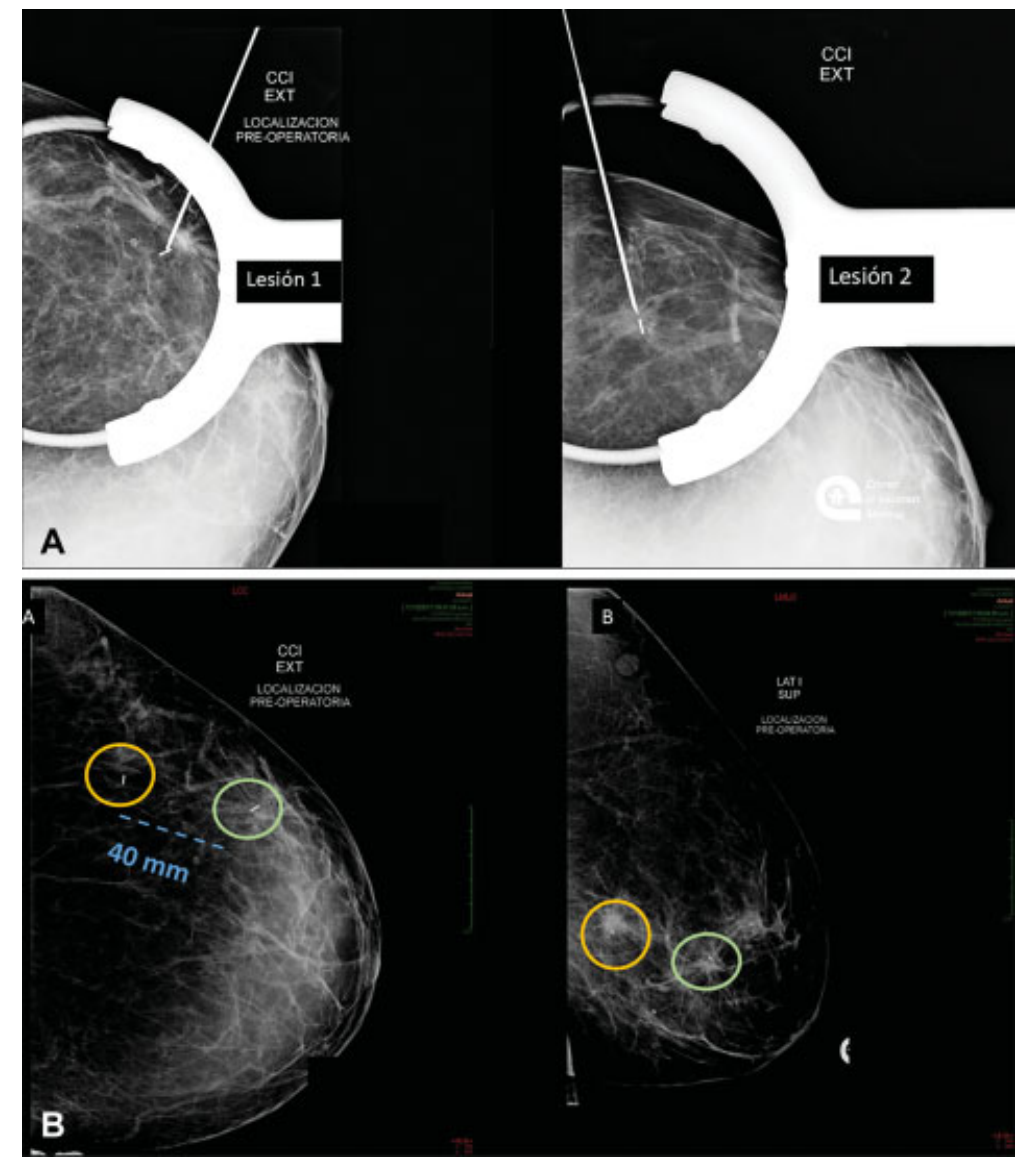

Fig. 13 Semilla doble/paréntesis localizando dos nódulos en hora 3 de mama izq. (A) Control de las semillas liberadas(B) Mamografías para enviar a quirófano con las dos lesiones y respectivas semillas separadas por $40 \mathrm{~mm}$. 

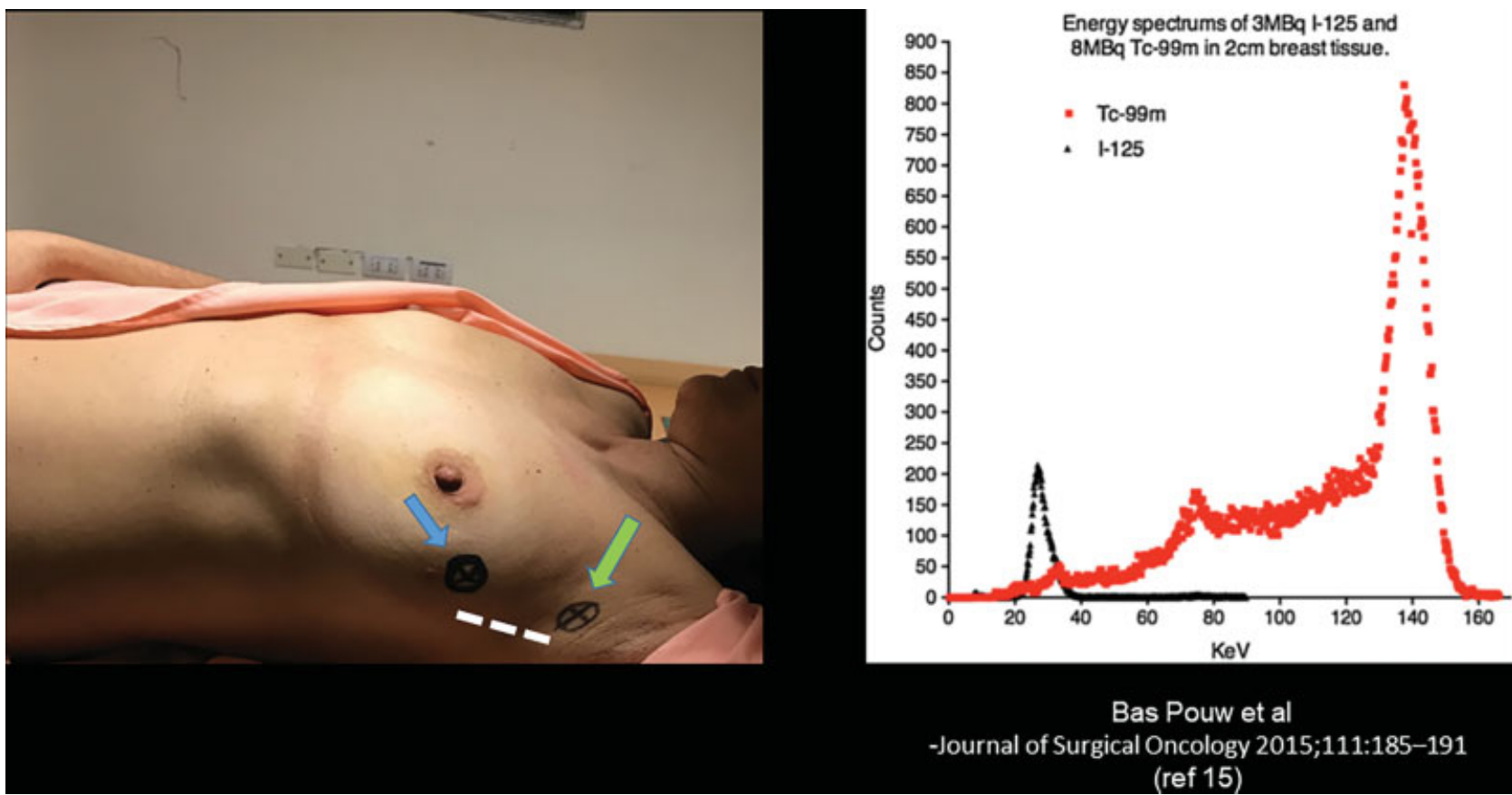

Fig. 14 (A) Reparos en la piel de los distintos picos de señal provenientes de la semilla (flecha azul) y ganglio centinela (flecha verde). (B) Espectros de energía del Tc-99m (140kev) y l-125 (27kev), ambos picos discriminables por la sonda de gamma probe.

discriminaron efectivamente los diferentes picos de energía del Tc-99y del Iodo-125 (- Fig. 14).

\section{Conclusión}

La técnica de localización de lesiones de la mama en nuestro país se basó casi exclusivamente en la inserción de alambres con arpones e inyección de carbón, por cuanto la utilización de semilla radioactiva parecía una meta muy lejana.

En nuestro medio, logramos finalmente el reconocimiento de la práctica y habiendo contribuido a su regulación es que estimulamos a implementarla responsablemente en aquellos centros interesados, consultando a la ARN, Subgerencia Control de Aplicaciones Médicas, Sector Medicina Nuclear,

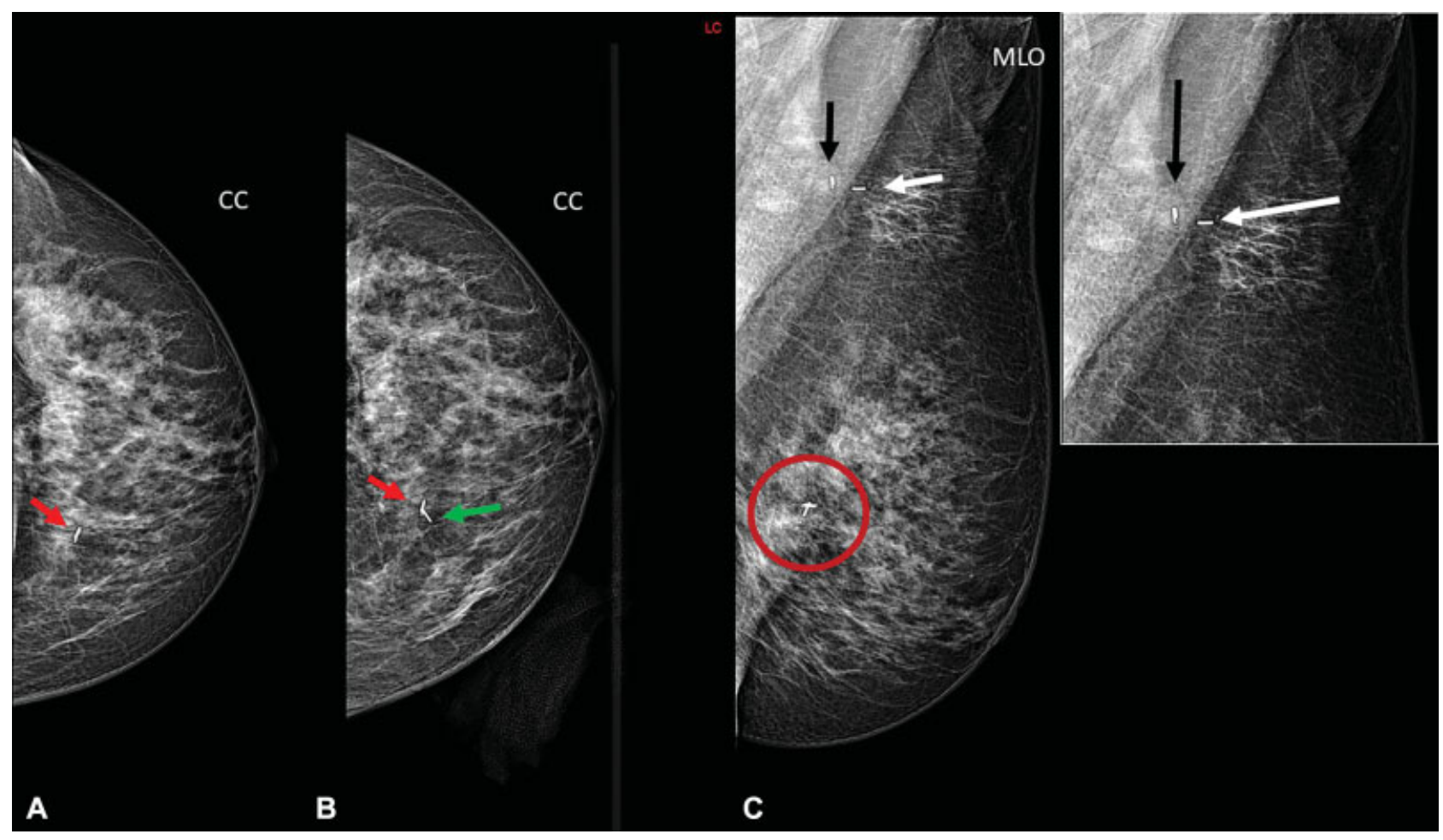

Fig. 15 Semillas marcando clips en lesión y ganglio axilar izquierdos (A) CC, clip en lesión biopsiada con US (flecha roja); (B) CC, semilla marcando el clip (flecha verde); (C) MLO, semilla (flecha blanca) y clip (flecha negra) en ganglio axilar biopsiado. 
los pasos a seguir, citando nuestra experiencia y solicitando ser incluidos siguiendo las condiciones y norma ya aprobadas, que se pueden resumir en el respeto, honra y registro de "La Ruta de la Semilla."

El desarrollo exige una labor conjunta entre los servicios de medicina nuclear e intervencionismo mamario vinculados en una relación sólida y estable.

En el período de 13 meses a partir de la autorización, hemos percibido un incremento exponencial del uso y su extensión a la localización de ganglios centinelas de la mama biopsiados y clipados (-Fig. 15). ${ }^{21-25}$

Está pendiente la localización de ganglios en otros territorios (cervicales, etc.). ${ }^{26}$

\section{Responsabilidades éticas}

Protección de personas y animales. Los autores declaran que para esta investigación no se han realizado experimentos en seres humanos ni en animales.

Confidencialidad de los datos. Los autores declaran que han seguido los protocolos de su centro de trabajo sobre la publicación de datos de pacientes.

Derecho a la privacidad y consentimiento informado. Los autores declaran que en este artículo no aparecen datos de pacientes.

\section{Conflicto de Intereses}

Los autores declaran no tener ningún conflicto de intereses.

\section{Bibliografía}

1 Hall FM, Kopans DB, Sadowsky NL, Homer MJ. Development of wire localization for occult breast lesions: Boston remembrances. Radiology 2013;268(03):622-627

2 Chan BK, Wiseberg-Firtell JA, Jois RH, Jensen K, Audisio RA. Localization techniques for guided surgical excision of nonpalpable breast lesions. Cochrane Database Syst Rev 2015;31 (12):CD009206. Doi: 10.1002/14651858.CD009206.pub2

3 De Cicco C, Pizzamiglio M, Trifirò G, et al. Radioguided occult lesion localisation (ROLL) and surgical biopsy in breast cancer. Technical aspects. QJ Nucl Med 2002;46(02):145-151

4 Gray RJ, Salud C, Nguyen K, et al. Randomized prospective evaluation of a novel technique for biopsy or lumpectomy of nonpalpable breast lesions: radioactive seed versus wire localization. Ann Surg Oncol 2001;8(09):711-715

5 Gray RJ, Pockaj BA, Karstaedt PJ, Roarke MC. Radioactive seed localization of nonpalpable breast lesions is better than wire localization. Am J Surg 2004;188(04):377-380

6 Hughes JH, Mason MC, Gray RJ, et al. A multi-site validation trial of radioactive seed localization as an alternative to wire localization. Breast J 2008;14(02):153-157

7 Jakub JW, Gray RJ, Degnim AC, Boughey JC, Gardner M, Cox CE. Current status of radioactive seed for localization of non palpable breast lesions. Am J Surg 2010;199(04):522-528

8 Alderliesten T, Loo CE, Pengel KE, Rutgers EJ, Gilhuijs KG, Vrancken Peeters MJ. Radioactive seed localization of breast lesions: an adequate localization method without seed migration. Breast J 2011;17(06):594-601. Doi: 10.1111/j.1524-4741.2011.01155.x

9 Dauer LT, Thornton C, Miodownik D, et al. Radioactive seed localization with 125 I for nonpalpable lesions prior to breast lumpectomy and/or excisional biopsy: methodology, safety, and experience of initial year. Health Phys 2013;105(04):356-365. Doi: 10.1097/HP.0b013e31829c03e1
10 Sung JS, King V, Thornton CM, et al. Safety and efficacy of radioactive seed localization with I-125 prior to lumpectomy and/or excisional biopsy. Eur J Radiol 2013;82(09):1453-1457

11 Barentsz MW, van den Bosch MA, Veldhuis WB, van Diest PJ, Pijnappel RM, Witkamp AJ. Radioactive seed localization for nonpalpable breast cancer. Eur J Cancer 2012;48(01):S215. Doi: 10.1002/bjs.9068

12 Ahmed M, Douek M. Radioactive seed localisation (RSL) in the treatment of non-palpable breast cancers: systematic review and meta-analysis. Breast 2013;22(04):383-388. Doi: 10.1016/j. breast.2013.04.016

13 Loving VA, Edwards DB, Roche KT, et al. Monte Carlo simulation to analyze the cost-benefit of radioactive seed localization versus wire localization for breast-conserving surgery in feefor-service health care systems compared with accountable care organizations. AJR Am J Roentgenol 2014;202(06):1383-1388. Doi: 10.2214/AJR.13.11368

14 Pouw B, de Wit-van der Veen LJ, Stokkel MP, Loo CE, Vrancken Peeters MJ, Valdés Olmos RA. Heading toward radioactive seed localization in non-palpable breast cancer surgery? A metaanalysis. J Surg Oncol 2015;111(02):185-191

15 Jakub J, Gray R. Starting a radioactive seed localization program. Ann Surg Oncol 2015;22(10):3197-3202. Doi: 10.1245/s10434015-4719-5

16 Bennett J, Pieri A, Cain H. Wire versus Radiactive Seed in the Localisation of Nonpalpable Breast Lesions: A Systematic Review. Eur J Surg Oncol 2018;44(06):862-918

17 Zamburlini M, Keymeulen K, Bemelmans M, Brans B, Kemerink GJ. Comparison of sentinel gamma probes for $99 \mathrm{mTc}$ breast cancer surgery based on NEMA NU3-2004 standard. Nucl Med Commun 2009;30(11):854-861

18 Pavlicek W, Walton HA, Karstaedt PJ, Gray RJ. Radiation safety with use of I-125 seeds for localization of nonpalpable breast lesions. Acad Radiol 2006;13(07):909-915

19 Graham RP, Jakub JW, Brunette JJ, Reynolds C. Handling of radioactive seed localization breast specimens in the pathology laboratory. Am J Surg Pathol 2012;36(11):1718-1723

20 Al-Hilli Z, Glazebrook KN, McLaughlin SA, et al. Utilization of Multiple I-125 Radioactive Seeds in the Same Breast is Safe and Feasible: A Multi-institutional Experience. Ann Surg Oncol 2015; 22(10):3350-3355. Doi: 10.1245/s10434-015-4749-z

21 Straver ME, Loo CE, Alderliesten T, Rutgers EJ, Vrancken Peeters MT. Marking the axilla with radioactive iodine seeds (MARI procedure) may reduce the need for axillary dissection after neoadjuvant chemotherapy for breast cancer. Br J Surg 2010;97 (08):1226-1231. Doi: 10.1002/bjs.7073

22 Donker M, Straver ME, Wesseling J, et al. Marking axillary lymph nodes with radioactive iodine seeds for axillary staging after neoadjuvant systemic treatment in breast cancer patients: the MARI procedure. Ann Surg 2015;261(02):378-382

23 Caudle AS, Yang WT, Mittendorf EA, et al. Selective surgical localization of axillary lymph nodes containing metastases in patients with breast cancer: a prospective feasibility trial. JAMA Surg 2015;150(02):137-143. Doi: 10.1001/jamasurg.2014.1086

24 Pouw B, der Veen LJ, Hellingman D, et al. Feasibility of preoperative (125)I seed-guided tumoural tracer injection using freehand SPECT for sentinel lymph node mapping in non-palpable breast cancer. EJNMMI Res 2014;4:19

25 Gobardhan PD, de Wall LL, van der Laan L, et al. The role of radioactive iodine-125 seed localization in breast-conserving therapy following neoadjuvant chemotherapy. Ann Oncol 2013; 24(03):668-673. Doi: 10.1093/annonc/mds475

26 Hassing CMS, Tvedskov TF, Kroman N, et al. Radioactive seed localisation of non-palpable lymph nodes - A feasibility study. Eur J Surg Oncol 2018;44(05):725-730. Doi: 10.1016/j.ejso. 2018.02.211 